\title{
Transatlantica
}

Revue d'études américaines. American Studies Journal

\section{Mazen Naous, Poetics of Visibility in the Contemporary Arab American Novel}

\section{Sara Arami}

\section{(2) OpenEdition}

\section{Journals}

Electronic version

URL: https://journals.openedition.org/transatlantica/14606

DOI: 10.4000/transatlantica. 14606

ISSN: $1765-2766$

\section{Publisher}

Association française d'Etudes Américaines (AFEA)

\section{Electronic reference}

Sara Arami, "Mazen Naous, Poetics of Visibility in the Contemporary Arab American Novel", Transatlantica [Online], 2 | 2019, Online since 15 September 2020, connection on 31 January 2023. URL: http:// journals.openedition.org/transatlantica/14606 ; DOI: https://doi.org/10.4000/transatlantica.14606

This text was automatically generated on 31 January 2023.

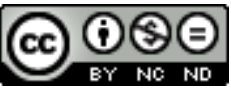

Creative Commons - Attribution-NonCommercial-NoDerivatives 4.0 International - CC BY-NC-ND 4.0

https://creativecommons.org/licenses/by-nc-nd/4.0/ 


\title{
Mazen Naous, Poetics of Visibility in the Contemporary Arab American Novel
}

\author{
Sara Arami
}

\section{REFERENCES}

Mazen Naous, Poetics of Visibility in the Contemporary Arab American Novel, Columbus: Ohio State University Press, 2020, 209 pages, ISBN N 9780814214299 (cloth) / ISBN

9780814277751 (ebook).

Paperback version $34.72 €$, Hardcover version $127.90 €$

1 Mazen Naous' Poetics of Visibility in the Contemporary Arab American Novel is a brilliant literary investigation into a selected corpus of today's Arab American fiction writers. What sets Naous' analyses apart from many other attempts at reading the writings of contemporary Arab American literary authors is his effort to avoid focusing solely on the political agendas of the novels carried out through the content of the works in question. Instead, he attempts to unravel the poetics of the works of fiction as they construct and render the political objectives of their authors visible. In other words, Naous treats his selected corpus first and foremost as works of literature highlighting the necessity that they should be read as such. Indeed, the political context of post-9/11 America has often led critics and commentators alike to focus primarily on the implicit and explicit messages that Arab American authors weave into their writing to the detriment of the literary qualities of their work. Such readings, as valuable as they might be in getting those messages heard, hinder the recognition of the literary merits of contemporary Arab American novels and thus their inclusion in the canon. This, in turn, works against the authors' agenda of rendering Arab American presence in the U.S. visible in all its heterogeneity and complexity countering the reductive media representations.

2 As such, Naous' project in Poetics of Visibility is a worthy one. Arab American novels are first and foremost works of fiction and should be read as such in the aim of being 
rightly placed among other works of literature, especially those written by diverse minority writers. Such a positioning will in turn allow for possibilities for comparative readings and open up enriching perspectives. To carry out this project, Poetics of Visibility focuses on four contemporary Arab American writers in five distinct chapters: Rabih Alameddine (Lebanese American), Diana Abu-Jaber (Palestinian American), Mohja Kahf (Syrian American) and Laila Halaby (Jordanian American). The book also includes a thirteen-page introduction and a six-page conclusion. In each of the five body chapters, Naous focuses on one work of fiction and among the authors, Diana Abu-Jaber gets the advantage of having two of her novels analyzed.

In the introduction to the volume, entitled "Poetics of Visibility, Visible Poetics," Naous sets on the essential task of explaining the context of Arab American in/visibility pre and post-9/11 as well as the manner in which Arab American presence in the U.S. has come to be viewed synecdochically. In other words, he goes on to explain how a few terrorists have come to stand in for all Arabs and Muslims despite their heterogeneities and diverse origins. The introduction further attests to the author's aim of focusing on the selected corpus' aesthetics and analyzing its "artistic innovation" which he claims allows for "Arab Americans to emerge as visible transcultural citizens with transnational and transpoetic frameworks" (Naous 5). The author further expands on what the term poetics in the title stands for and how focusing on "the poetics of visibility" in the selected novels would help highlight their role in undermining dominant views of Arab Americans and unravel "new transcultural possibilities" (Naous 7). In practice, the focus on poetics is carried out through the analysis of a certain aspect of the novels in question in each chapter; an element which allows Naous to explore the possible links between the formal features of the novels with their political agendas.

The first chapter of Poetics of Visibility is dedicated to the study of Lebanese American Rabih Alameddine's Koolaids: The Art of War, a debut published in 1998. The novel takes place in San Francisco and Beirut and draws innumerous comparisons through themes and structure between the two sites with a focus on the AIDS epidemic and the Lebanese civil war. The structure of the novel is complex as the work is divided into various vignettes which are seemingly unrelated and disjointed in such a manner as to reflect the chaos brought about by the events it treats. In this chapter, entitled "Disease as Queer Cure," Naous takes what he terms "a poetics of AIDS dementia" as his guide in reading the novel. The "poetics of AIDS dementia" leads to "a poetics of repetition" presented as a counterpoint to the disparate vignettes that make up the novel. It further allows for interpretive possibilities which challenge singular modes of reading and ultimately singular modes of being. Naous provides ample examples of how the "poetics of AIDS dementia" and the "poetics of repetition" are at work in the novel and how they help form complex and multiple readings of the vignettes. In reading the sample vignettes in order to illustrate his point, Naous takes a step further and engages in the analysis of Alameddine's paintings Hélas \#251, \#119 and \#185, trespassing the boundaries of literature and exploring the possibilities of interpretation by reading the paintings and the novel's vignettes alongside one another. Naous further presents the novel's pattern of repetition as related to the Middle Eastern tradition of oral storytelling. The point of view put forward by the chapter and the examples brought to support it are novel and extremely engaging and Naous does not hesitate to use his 
expertise in Middle Eastern and Muslim culture in order to propose fresh reading of the vignettes he focuses on.

It is this same knowledge of Middle Eastern cultures in combination with a savviness in music which comes into play in the second chapter of the volume to help the author present a stimulating analysis of Diana Abu-Jaber's Arabian Jazz. Published in 1993, Arabian Jazz is the second pre-9/11 novel to be studied by Naous. In "Blue Notes and Accented Rhythms," the author takes African American jazz and the blue note as its poetics and claims that improvisation adds "a formal and poetic dimension that is crucial to the novel's [Arabian Jazz's] expansive approach to Arab American identity and visibility" (Naous 55). Naous further attests to the linguistic manifestation of improvisation throughout Arabian Jazz. A thorough analysis of the names of the protagonists and their translations, along with their various meanings and implications, is taken into account in order to back the author's point of view. Naous maintains that improvisation as such plays a significant role in disrupting norms of every kind in the context of the United States. He further focuses on one of the protagonist's habit of drumming a specific jazz piece, "Naima" by John Coltrane, in order to support his reading further. The analysis carries on to explain how in the interrelationship between the untranslated names of the characters and the title of the novel improvisations are at work and demonstrate how Arabian jazz comes to life in the novel. Although the proposed readings are extremely interesting and the author's profound knowledge of music results in fresh and unprecedented viewpoints, the fact that many of the interpretations are based on translations of proper names, rather than other forms of the use of language in the novel, undermines the claim to linguistic improvisation to a certain degree. Eventually, the use of untranslated Arabic words in the text of the novel is interpreted as a challenge to the adequacy of English in representing issues that concern the Arab American characters of the novel. As such, the jazz poetics of the novel are considered to allow the Arab American characters to connect to other minorities such as African, Asian, Native, Irish Americans and so on. Subsequently, they "disrupt the dominant perception of Arab Americans in the US" impelling "transcultural modes of visibility" (Naous 85).

6 Poetics of Visibility takes Mohja Kahf's The Girl in the Tangerine Scarf (2006) as its subject of study in the third chapter entitled "Sign after Sign." Although written post 9/11, the novel is set in the era preceding the attacks on the twin towers. For Naous, the novel aims to demonstrate that Islamophobic and anti-Muslim attitudes have existed long before 9/11. Because the novel deals mainly with life in a Muslim community, Naous explains, critics have mostly treated it as an issues novel and ignored its aesthetic values. The author admits to have had the same feeling towards The Girl in the Tangerine scarf upon a first reading, but to have changed his opinion drastically after subsequent readings. In this chapter, the author takes signs in their various forms, as his guide in the interpretation of the novel. The chapter focuses on the representation of material signs such as highway and billboard signs in the text and also takes the epigraphs that begin the chapters of the novel as intersectional signs that contribute to the production of meaning. The analysis of the latter results in the presentation of brilliant accounts of the interconnections and cross-fertilizations among the epigraphs and between the epigraphs and the text of the novel. It is in the third chapter of the volume as well that the personal interest of the author for the themes he discusses is felt the most. At times, this interest results in generalized comments that are not supported by reference to other sources and this at the risk of slightly undermining the objectivity of 
the study. Such comments, however, should be taken as proof of the author's passionate concern about the topics he deals with and do not take away the worth of the meticulous analyses carried out throughout the volume in any way. In a similar manner as in the previous chapter, links are established between the experiences of the Arab American characters of the novel and those of other minorities, specifically Native Americans and African Americans. Pursuing the former links further would have rendered Naous' study of The Girl in the Tangerine Scarf even more captivating. The last point to be noted about the third chapter of Poetics of Visibility is that, as is with the case of practically all studies of Kahf's novel, it engages in the study of the representations of the veil/scarf and the protagonist's evolving feelings towards veiling. Finally, Naous argues that the poetics of signification in the novel serve both as a criticism to the Western practices of representing the hijab as oppressive and backwards and equally to a historicization of Islamophobic practices in the U.S. while simultaneously revealing the heterogeneity of the Muslim communities.

7 Islamophobic reactions and anti-Arab sentiments are the topics of Once in a Promised Land (2007), the novel that Poetics of Visibility takes as its object of study in the fourth chapter. "Anagrams of Identity" focuses on Laila Halaby's Once in a Promised Land (2007), the only novel of the selected corpus that deals with the aftermath of 9/11 directly. In the same manner as in the second chapter, here, the author focuses on the use of language in the novel, more specifically on the use of anagrams. The aim in the examination of the formal aspects of the novel which also extend the analysis of such aspects of the novel as the story-telling and the realistic narrative, is to demonstrate the manner in which these features work together to "acknowledge the failures of translational mediation and agency with a setting of cultural backlash" (Naous 122). The focus on the characters' Arabic names and their English translations, which seems to be one of the author's favorite strategies in his readings, comes to play as well in the analysis of Once in a Promised Land. Moreover, the structure of the chapters in the novel is compared to anagrams. The author claims that this strategy is used in order to render the lives of Arab Americans and other Americans visible. Such a reading of the structure of Halaby's novel is unprecedented and offers new possibilities of interpretation which are partially investigated throughout the fourth chapter. For Naous, thus, it is the anagrammatic play, both linguistic and structural, that gives aesthetic value to Halaby's novel and uncovers the complexity of the immigrant experience.

8 The last chapter of Naous' study of Arab American fiction goes back to focus on an author who has already been the subject of analysis in chapter two: Diana Abu-Jaber. This time, it is Abu-Jaber's second novel, Crescent (2003), which becomes the topic of "Reframing Infidelity." The title of the fifth chapter leaves no secret as to the selected strategy for reading the novel. For Naous, it is the transgression of all types of boundaries, be it "formal, poetic, cultural or lingual" (Naous 149) in Crescent which allows for a "reimagining and reimaging" (Naous 150) of Arab Americans. Here, the author discusses the novel's connections to three literary masterpieces, that is Othello, The Arabian Nights and The Odyssey, on the one hand to focus on the themes of fidelity and infidelity and on the other, to demonstrate how Crescent diverges from the stories that inspire it. This chapter, along with the first one, includes some of the most intriguing passages of the volume as the author exhibits much expertise and ease in dealing with the intertexts. To end the chapter, Naous examines the appropriation of the figure of the storyteller in Crescent, and the political and aesthetic implications such 
an appropriation might have for an understanding of the novel. Eventually, the novel's multiple infidelities on the thematic level are shown to spur cross-cultural dialogue.

The concluding chapter, "Arab American Polyphonics" takes a political tone. Here, the author highlights the real impact of racist anti-Muslim representation in the media on the human lives of Arabs and Muslims both inside the U.S. and abroad. He makes this point creatively by drawing on Crescent's frame story. The conclusion further illustrates how the novels of the selected corpus work to place Arab Americans as transcultural citizens in the United States and assert their heterogeneity. In an ultimate gesture to assert his methodology, the author ends the volume by establishing Arab American polyphonics as "a crucial poetics for both individual and collective visibilities on Arab American transcultural and transpoetic terms" (Naous 193).

On the whole, Naous' volume achieves its aim of underlining the artistic and the aesthetic in the Arab American novels of its corpus and to shift the rather prevalent mode of approaching the Arab American novel from a solely political stance. Poetics of Visibility in the Contemporary Arab American Novel is a must-read for all the scholars of Arab diasporic literature. Naous' invaluable efforts should be taken up by other literary specialists in the field in order to firmly establish Arab American fiction's place among aesthetically valued works of literature. As mentioned at the beginning of this review, such a positioning would unravel enriching and novel outlooks and more importantly, allow for the voices of Arab American authors to be heard, leading to enhanced Arab American visibility in the United States.

\section{INDEX}

Subjects: Recensions

\section{AUTHORS}

\section{SARA ARAMI}

Université de Strasbourg, SEARCH UR 2325 